\title{
EDITORIAL
}

\section{Issues and Impact of COVID-19 on Surgical Services in Northern Borneo, Sabah}

Firdaus Hayati' ${ }^{*}$, Nik Amin Sahid Nik Lah¹, Andee Dzulkarnaen Zakaria², Syed Sharizman Syed Abdul Rahim³, Nornazirah Azizan ${ }^{4}$

\section{Department of Surgery, Sciences, Universiti Sains Malaysia, Kelantan, Malaysia \\ ${ }^{3}$ Department of Public Health Medicine, \\ *Corresponding author's email: firdaushayati@gmail.com; m_firdaus@ums.edu.my}

Faculty of Medicine and Health Sciences, Universiti Malaysia Sabah, Sabah, Malaysia

2 Department of Surgery, School of Medical Faculty of Medicine and Health Sciences, Universiti Malaysia Sabah, Sabah, Malaysia ${ }^{4}$ Department of Pathology and Microbiology, Faculty of Medicine and Health Sciences, Universiti Malaysia Sabah, Sabah, Malaysia

DOI: https://doi.org/10.51200/bjms.vi.3538
Globally, everyonehasgonethroughanunusual and remarkable period during the COVID-19 pandemic. The pandemic has affected various sectors in the country and implicated society. Important services including the health care system, particularly in surgery, have raised challenges and issues that need to be sorted out. This action is prudent to justify the balance in between care on preventing the spread of COVID-19 infection and at the same time providing surgical services. In this article are the perspectives on how we elicit the issues and the solutions in providing surgical services during the COVID-19 pandemic in our state, Sabah.

The COVID-19 pandemic has released turmoil all over the world. Respective governments and other organisations are actively responding to curb the spread of the damaging virus. As of 26th June 2021, there were more than 180 million confirmed COVID-19 cases reported worldwide with an average number of 370,000 cases reported per day, in addition to global deaths of almost 4 million (World Health Organization [WHO], 2021). Industrial sectors such as tourism, food production, finance, trading, and properties as well as healthcare services have been greatly affected. Many hospitals and health institutions especially the tertiary centres have been involved in this calamity. Among all crucial services in the hospital, surgery and its subspecialties are among the worst units being affected. In general, they can be broadly 
categorized into (1) surgical personnel, (2) surgical practice and services, and (3) surgical procedures on patients.

\section{Surgical Personnel}

Surgeons and surgical staff are among the healthcare personnel that are heavily involved from staff nurses in the clinic, gastrointestinal assistants in the endoscopy room, assistant nurses in the operation theatre, medical officers, postgraduate surgical trainees and surgeons. All are involved in providing equivalent responsibility in managing surgical patients.

Post-graduate training is a core process in preparing the nation with a continuous supply of new-breed surgeons and the need for personnel within the fraternity. However, due to this pandemic, the whole training schemes are needed to be channelled for a greater need, fighting COVID-19. Speciality rotation, exposure to elective procedures, end of posting assessment, and speciality exit examination are affected and postponed to a later date during this MCO. The structures of exit examination in surgery speciality programs are mostly face-to-face in which involve more in the psychomotor domain. It is yet to be determined whether the assessment system requires any revamp to suit the new norm post-pandemic event. Hence, it delays the production of a new breed of surgeons in the country.

Human resources are restructured to fill up the need to ensure the COVID-19 core front liners on screening and managing COVID-19 services are at optimum. Medical officers are being relocated to help the frontliners in the screening team as the manpower available is inadequate to battle the pandemic. They have been deployed to other services and units to provide much-needed care, again for the greater benefit. The training of housemen in a tertiary centre will be slightly affected. They are the people who have freshly graduated from medical school, require training in the medical field to the fullest. Being involved in the COVID-19 pandemic, their training will slightly deviate from the norms. Usual round, common elective cases, and clinic and surgery sessions, all are catered following the standard operating procedure of COVID-19.

\section{Surgical Practice and Services}

There are several modifications in surgical practices and services that need to be made during the COVID-19 pandemic. The first action that was taken by the nation's health department and the involved tertiary hospitals is by preparing all the possibilities for COVID-19 to spread out of control including higher education institutions (Mukhsam et al., 2020). This organization and preventive approaches are mandatory in the phase of MCO. This is to ensure the capability and competency as well as preservation of financial and human resources. In Sabah, one of the tertiary hospitals was converted to a COVID-19 hospital. All surgery-related services including the vital surgeries and devices for surgery were transferred to another hospital. Even though the process of transferring all the equipment is following the standard of procedure, the risk of malfunction and loss throughout the transfer process may still happen.

Due to geographical challenges and lack of surgeons, we have to adopt the initiation of visiting surgery services in the district areas. However, this service has to be put on halt due to this pandemic. This is to ensure that the enforcement of human resources in surgery is centred on tackling COVID-19 matters at tertiary centres. Previously, the monthly visits to the involved district can help to reduce the high burden of cases backlog at the district level. Any low-risk procedures can be performed during these visits, hence reducing the cases in tertiary centres.

To avoid overcrowding in the waiting area, the number of cases for clinic appointments is being cut down. Patients 
are selectively chosen to be seen in the clinic. Chairs in the waiting areas are spaced out to avoid physical contact and social interaction. Waiting time for speciality consultations is now being pushed longer than before. Certain hospitals refuse to accept patients with the slightest of respiratory symptoms in fear of the COVID-19.

\section{Surgical Procedures on Patients}

Any elective cases such as benign cases and certain cancer patients need to be postponed until the infection has been considered cleared by the authority. Emergency and complicated cancer patients with bleeding, obstructed, or perforated tumours are deemed to be surgically intervened as early as possible. A decision has been made at many hospitals and health institutions to postpone elective operations in keeping with recommendations by the American College of Surgeons (Begley et al., 2020). Upon managing these patients, participation and involvement of all surgeryrelated personnel must be minimal. Duration of the surgery needs to be fastened, the number of assistants is limited, and complicated or big cases are to be performed by senior medical officers or surgeons.

Better to add different hospitals in peninsula Malaysia and Sabah's surgical management procedure during COVID-19 both inpatient and outpatient departments and compare with other countries management during the same period.

Operation theatre (OT) is the most important area in surgery as it is the place where most elective and emergency cases reside. Activities of going in and out of the OT are prohibited. Personnel present in the OT during surgery must not leave the room. Any sudden essential retrieval of necessary equipment should be done by staff outside the OT. After finishing the cases, logistics should decontaminate the OT before the next procedure takes place, to reduce possible air contamination. After the case, all areas at risk of contamination must be cleaned and disinfected. Efforts should be made to minimize the contamination risk associated with specimens sent to the pathology department.

Both patients and treating doctors are at high risk to be exposed to the COVID-19 virus through the aerosol-generating procedure (AGP) such as laparoscopic surgery and endoscopic procedures. The choices between open and laparoscopy are debatable among the surgical fraternity. Any cases that can be treated using an open technique with minimal risk are advised to do so. Laparoscopic surgery is best to be avoided to reduce the risk of viral transmission from AGP. The possibility of viral contamination can occur via the possible release of a virus in the form of an aerosol with CO2 (Pryor, 2020). During laparoscopy, a jet of air is to be blown through the trocars giving a chimney effect. Consequently, the operating theatre will be concentrated with aerosol materials, especially viruses hence exposing the operating staff to viral contamination (Mowbray et al., 2020). Few recommendations have been suggested for laparoscopy among unknown COVID-19 status patients (Joseph et al., 2020). Similarly, elective endoscopy procedures especially for diagnostic and screening purposes are withheld to give way to only emergency cases.

In conclusion, the COVID-19 pandemic has caused a huge implication to various areas and sectors in the services of surgery. Most importantly, protecting the health care personnel and patients are the utmost crucial aspect during this pandemic. The issues and challenges can highlight the authority and relevant parties to be prepared and react wisely to balance between further disease spread and providing surgical services to the community. 


\section{References}

Begley, J. L., Lavery, K. E., Nickson, C. P., \& Brewster, D. J. (2020). The aerosol box for intubation in coronavirus disease 2019 patients: an insitu simulation crossover study. Anaesthesia, 75 (8), 1014 - 1021. https://doi.org/10.1111/ anae. 15115

Joseph, J. P., Joseph, A. O., Oomman, S., \& Jayanthi, N. (2020). Laparoscopic versus open surgery: aerosols and their implications for surgery during the COVID-19 pandemic. Eur Surg, 1 - 2. https://doi.org/10.1007/s10353-02000644-1

Mowbray, N. G., Ansell, J., Horwood, J., Cornish, J., Rizkallah, P., Parker, A., Wall, P., Spinelli, A., \& Torkington, J. (2020). Safe management of surgical smoke in the age of COVID-19. Br J Surg, 107 (11), 1406 - 1413. https://doi. org/10.1002/bjs.11679
Mukhsam, M. H., Jeffree, M. S., Pang, N., Syed Abdul Rahim, S. S., Omar, A., Abdullah, M. S., Lukman, K. A., Giloi, N., Salvaraji, L., Abd Karim, M. R., Saupin, S., Yeap, B. T., Mohd Hayati, M. F., Ibrahim, M. Y., Muhamad, A., \& Zainudin, S. P. (2020). A university-wide preparedness effort in the alert phase of COVID-19 incorporating community mental health and task-shifting strategies: Experience from a Bornean institute of higher learning. American J Trop Med Hyg, 103 (3), 1201 - 1203. https://doi.org/10.4269/ ajtmh.20-0458

Pryor, A. (2020). SAGES and EAES recommendations regarding surgical response to COVID-19 crisis. https://www.sages.org/recommendationssurgical-response-covid-19/

World Health Organization (WHO). (2021). Weekly epidemiological update on COVID-19 29 June 2021 (Edition 46). https://www. who.int/publications/m/item/weeklyepidemiological-update-on-covid-19---29june-2021 